\title{
Rapid Recognition of Isomers of Monochlorobiphenyls at Trace Levels by Surface-Enhanced Raman Scattering Using Ag Nanorods as a Substrate
}

Qin Zhou, Ye Yang, Jie Ni, Zhengcao Li, and Zhengjun Zhang ( $\varangle)$

Advanced Materials Laboratory, Department of Materials Science and Engineering, Tsinghua University, Beijing 100084, China

Received: 12 April 2010 / Revised: 22 April 2010 / Accepted: 22 April 2010

C The Author(s) 2010. This article is published with open access at Springerlink.com

\begin{abstract}
Isomers and homologues of organic pollutants are hard to distinguish-especially in trace amounts—due to the similarities in their physical and chemical properties. We report here that by identifying the Raman characteristics of isomers of monochlorobiphenyls, these compounds can be recognized, even at trace levels, by using the surface-enhance Raman scattering method with silver nanorods as a substrate. When dissolved in acetone, 2-, 3-, and 4-chlorobiphenyls were detected at a concentration of $10^{-8} \mathrm{~mol} / \mathrm{L}$, at which their characteristic Raman peaks were visible. This study may provide a fast, simple, and sensitive method for the detection and recognition of organic pollutants such as polychlorinated biphenyls.
\end{abstract}

\section{KEYWORDS}

Recognition, isomer, chlorobiphenyl, trace levels, SERS

\section{Introduction}

Persistent organic pollutants (POPs), e.g., dioxins, and polychlorinated biphenyls (PCBs), etc., are harmful and have polluted almost everywhere in the world [1]. The removal of these pollutants, which has aroused great research interest in recent years, requires techniques that are able to detect these compounds even at trace levels. This is because even in trace amounts in the environment, they can be accumulated at high dosage in human bodies through foods (vegetables, plants, animals, etc.) and cause severe health problems when they exceed the critical dose [1-3]. Currently, a combination of high-resolution gas chromatography and mass spectrometry is widely used as a powerful means for the detection of these compounds; this method is, however, expensive and time-consuming, and is not always able to distinguish isomers [4-7].

Materials with dimensions on the nanometer scale exhibit many interesting properties and may find opportunities in the detection of trace amounts of organic pollutants [8-11]. For example, using nanostructures of noble metals $(\mathrm{Cu}, \mathrm{Ag}$, and $\mathrm{Au})$ as the substrate, some organic species have been detected in trace amounts by surface-enhanced Raman scattering (SERS) [12-18]. The advantages of SERS are its high sensitivity, simplicity, fast detection speed, as well as its capability in the recognition of compounds. Therefore it is of interest to investigate the possibility of using SERS in detection/recognition of POPs such as PCBs. The difficulty of using SERS for PCBs is that they are

Address correspondence to zjzhang $@$ tsinghua.edu.cn 
insoluble in water, the solvent normally used in SERS measurements $[19,20]$. Besides, little is known about the characteristics of their Raman spectra, which are essential for the recognition of isomers.

Here, we report an experimental and theoretical study of the Raman spectra of biphenyl and monochlorobiphenyl isomers, from which the characteristics of their Raman spectra were obtained, and then describe the detection and recognition of these compounds in trace amounts using aligned Ag nanorods as the substrate.

\section{Experimental procedure}

The Raman spectra of biphenyl, and 2-, 3-, and 4-chlorobiphenyls were measured with a Renishaw Raman 100 spectrometer using a $633 \mathrm{~nm}$ He-Ne laser as the excitation source at room temperature. Powders

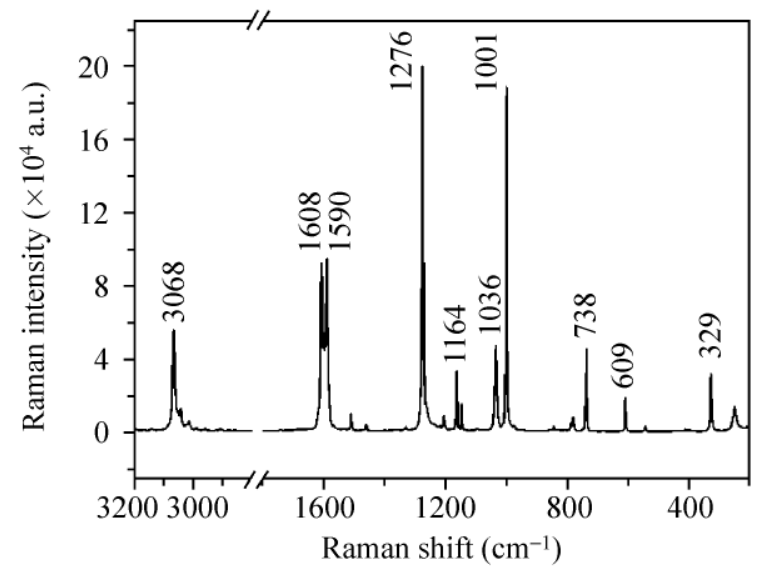

(a)

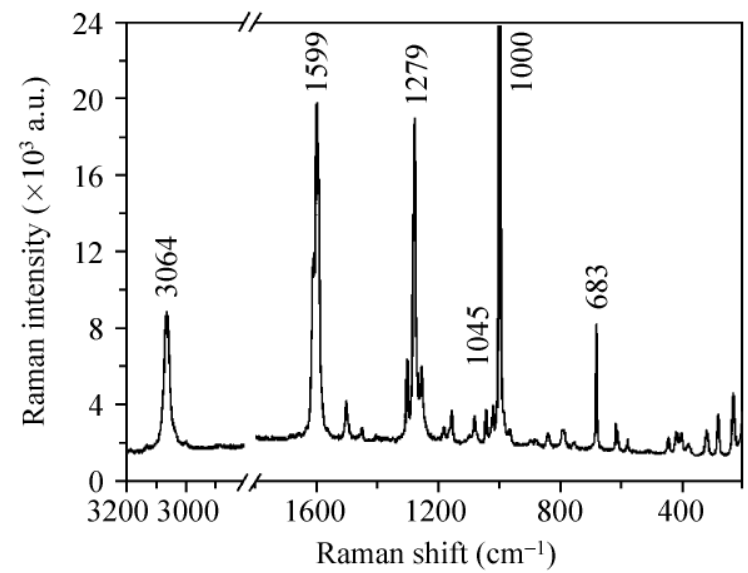

(c) of these compounds are commercially available from the AccuStandard Company. Simulation of the Raman spectra was performed by means of density functional theory using the Gaussian 03 program package in order to better understand the vibrational modes observed, and define the fingerprints of these compounds. For the SERS measurements, powders of chlorobiphenyls were dissolved in acetone to concentrations from $10^{-4}$ to $10^{-10} \mathrm{~mol} / \mathrm{L}$. The substrates were $\mathrm{Ag}$ nanorods prepared by electron beam deposition. The deposition of the Ag nanorods has been described elsewhere [21]. A small volume of each solution $(\sim 0.5 \mu \mathrm{L})$ was dropped on the surface of $\mathrm{Ag}$ nanorods, and acetone was blown away using a nitrogen flow.

\section{Results and discussion}

Figures 1(a)-1(d) show the measured Raman spectra

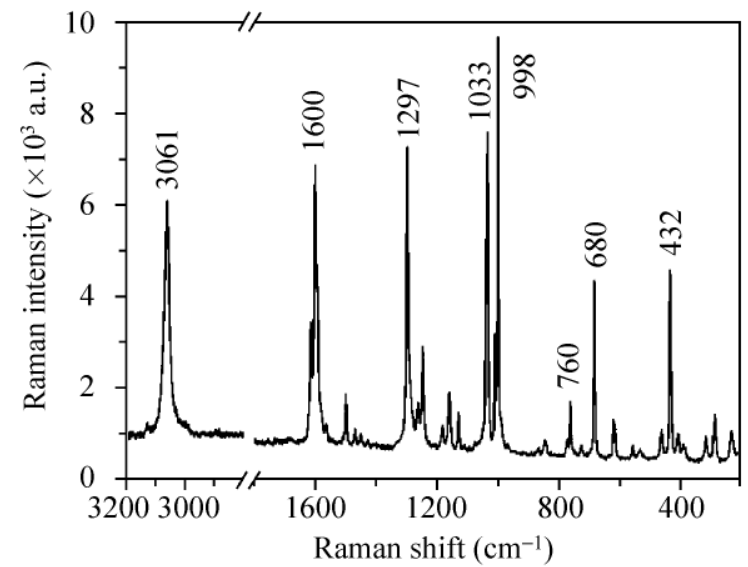

(b)

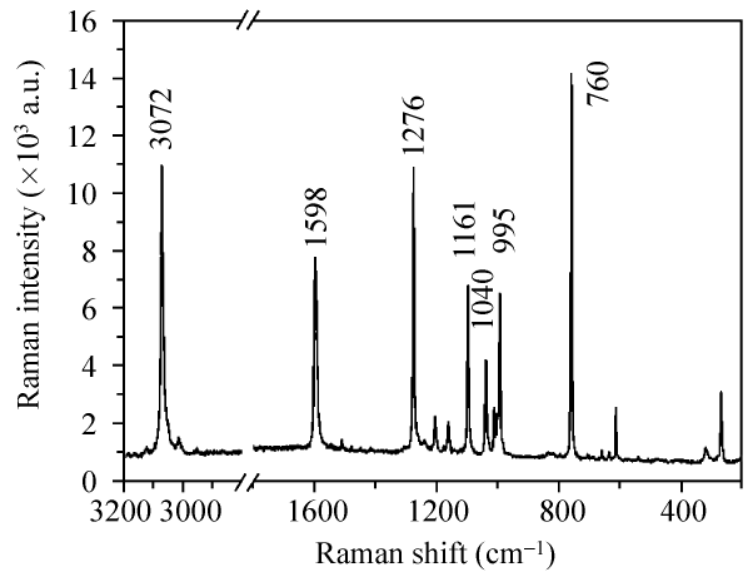

(d)

Figure 1 Raman spectra of (a) biphenyl; (b) 2-chlorobiphenyl; (c) 3-chlorobiphenyl; (d) 4-chlorobiphenyl, measured using powders commercially available from the AccuStandard Company 
of biphenyl, and 2-, 3-, and 4-chlorobiphenyl, respectively. Each material has strong peaks at $\sim 3065$, $1600,1280,1030$, and $1000 \mathrm{~cm}^{-1}$, demonstrating the common features of biphenyl and its derivatives. One may also notice differences between the Raman spectra of the four materials. For example: (1) biphenyl, 3- and 4-chlorobiphenyl all have a strong Raman peak around $1276 \mathrm{~cm}^{-1}$, while the corresponding peak for 2-chlorobiphenyl is at $1297 \mathrm{~cm}^{-1}$; (2) biphenyl has a strong peak at $738 \mathrm{~cm}^{-1}, 2$ - and 4-chlorobiphenyl have strong peaks at $\sim 760 \mathrm{~cm}^{-1}$, but there are no significant peaks for 3-chlorobiphenyl in this region; (3) both 2- and 3-chlorobiphenyl have strong peaks around $\sim 680 \mathrm{~cm}^{-1}$, while biphenyl and 4-chlorobiphenyl have no visible peak nearby; (4) only 2-chlorobiphenyl has a strong peak at $\sim 432 \mathrm{~cm}^{-1}$. The above features might be used to detect and distinguish between biphenyl, and 2-, 3, and 4-chlorobiphenyl.

To gain a clear understanding of these features, we performed simulations using density functional theory with the Gaussian 03 program package. The simulations were carried out by Becke's three-parameter hybrid method using the Lee-Yang-Parr correlation functional (B3LYP), and the LANL2DZ basis set [22]. Gaussian View was used to input data visually. The $\pi$ bond length of the benzene ring was set to be $1.409 \AA$, the $\sigma$ bond length between $\mathrm{C}$ and $\mathrm{H}$ atoms was set to be $1.088 \AA$, and the $\sigma$ bond length between $\mathrm{C}$ and $\mathrm{Cl}$ atoms was set to be $1.760 \AA$.

Table 1 lists the major vibrational modes of the four materials obtained by the above simulations. The common features in their experimental Raman spectra at $3065,1600,1280,1030$, and $1000 \mathrm{~cm}^{-1}$ (see Fig. 1), can be attributed to the $\mathrm{C}-\mathrm{H}$ stretching mode $\left(\sim 3100 \mathrm{~cm}^{-1}\right)$, the ring CCC stretching mode $\left(\sim 1650 \mathrm{~cm}^{-1}\right)$, the C-C bridge bond stretching mode $\left(\sim 1280 \mathrm{~cm}^{-1}\right)$, the $\mathrm{C}-\mathrm{H}$ bending in-plane mode (1050 to $\left.1100 \mathrm{~cm}^{-1}\right)$, and the CCC trigonal breathing mode $\left(\sim 1000 \mathrm{~cm}^{-1}\right)$, respectively.

Replacement of the $\mathrm{H}$ by $\mathrm{Cl}$ atom results in different changes in the three CCC bending (ring deformation) in-plane modes (with calculated Raman shifts of $760 \mathrm{~cm}^{-1}, 680 \mathrm{~cm}^{-1}$, and $460 \mathrm{~cm}^{-1}$ ) for 2-, 3-, and 4-chlorobiphenyl. Figures 2(a)-2(c) show the most intense CCC bending in-plane mode for 2-, 3-, and 4-chlorobiphenyl, respectively. For 2-chlorobiphenyl, the 2-5 direction CCC bending at $460 \mathrm{~cm}^{-1}$ is the strongest, the 3-6 direction CCC bending at $680 \mathrm{~cm}^{-1}$ is slightly weaker, while the $1-4$ direction bending at $760 \mathrm{~cm}^{-1}$ is weak. For 3-chlorobiphenyl, the $2-5$ direction bending mode is negligible, the $3-6$ direction bending mode is strong, while the 1-4 direction bending mode is weak. For 4-chlorobiphenyl, the 2-5 direction bending mode is negligible, the 3-6 direction bending mode is weak, while the $1-4$ direction bending mode is strong. These results are in agreement with the experimental measurements (Fig. 1), and suggest that the intensities of the CCC bending inplane modes can be used to distinguish between the three isomers.

The substrate used in the SERS measurements was Ag nanorods prepared by the electron beam deposition technique [21]. Figure 3 shows a typical scanning electron microscope (SEM) image of the Ag nanorods, taken with an FEI SEM (Quanta 200 FEG) working at $20 \mathrm{kV}$. Powders of 2-, 3-, and 4-chlorobiphenyl were dissolved in acetone and diluted to concentrations

Table 1 Major simulated vibrational modes for 2-, 3-, and 4-chlorobiphenyl

\begin{tabular}{lcccc}
\hline \multicolumn{1}{c}{ Vibrational mode } & $\begin{array}{c}\text { Raman shift } \\
\left(\mathrm{cm}^{-1}\right)\end{array}$ & $\begin{array}{c}\text { Raman intensity } \\
\text { 2-chlorobiphenyl }\end{array}$ & $\begin{array}{c}\text { Raman intensity } \\
\text { 3-chlorobiphenyl }\end{array}$ & $\begin{array}{c}\text { Raman intensity } \\
\text { 4-chlorobiphenyl }\end{array}$ \\
\hline C-H stretching & 3100 & 511 & 359 & 351 \\
CCC stretching & 1650 & 31 & 34 & 38 \\
C-C bridge bond stretching & 1280 & 50 & 50 & 62 \\
C-H bending in-plane & 1050 & 46 & 22 & 15 \\
Trigonal breathing & 1000 & 34 & 44 & 27 \\
CCC bending in-plane (1-4 direction) & 760 & 3 & 4 & 23 \\
CCC bending in-plane (3-6 direction) & 680 & 11 & 8 & 7 \\
CCC bending in-plane (2-5 direction) & 460 & 13 & 0 & 0 \\
\hline
\end{tabular}

\section{是 Springer}




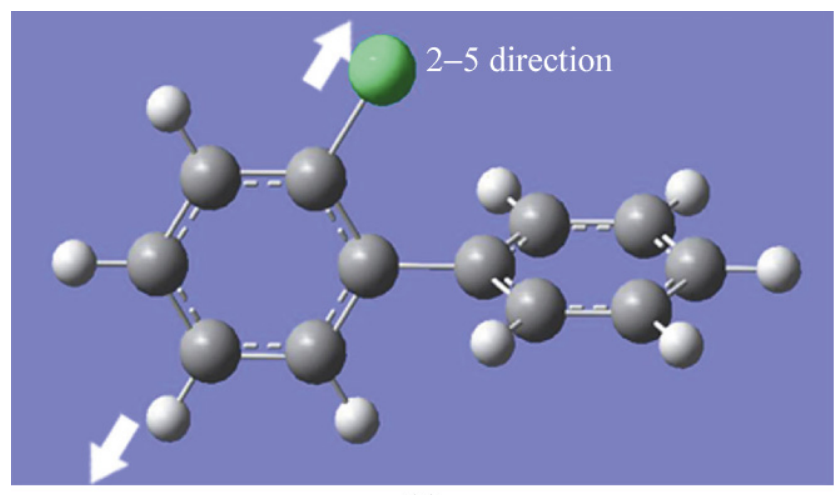

(a)

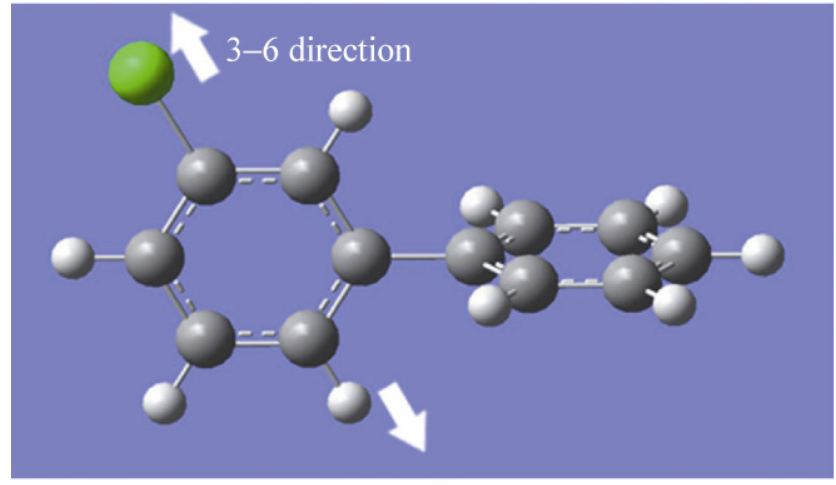

(b)

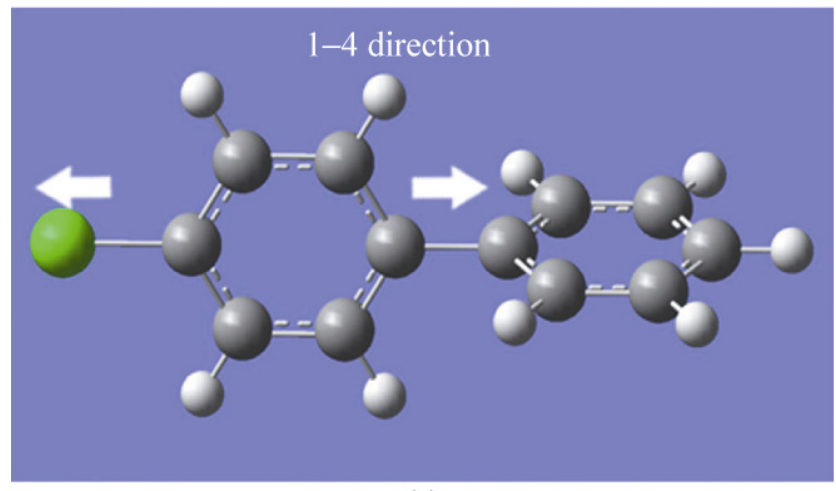

(c)

Figure 2 The most intense ring deformation in-plane modes for the three isomers of chlorobiphenyl: (a) 2-chlorobiphenyl; (b) 3-chlorobiphenyl; (c) 4-chlorobiphenyl

ranging from $10^{-4}$ to $10^{-10} \mathrm{~mol} / \mathrm{L}$. A small volume $(0.5 \mu \mathrm{L})$ of these solutions was dropped on $\mathrm{Ag}$ nanorods and the acetone was blown away using a gentle nitrogen flow. Figures 4(a)-4(c) show the SERS spectra of the 2-, 3-, and 4-chlorobiphenyl, respectively, at various concentrations. The accumulation time of each spectrum was fixed at $30 \mathrm{~s}$ per $100 \mathrm{~cm}^{-1}$, and we used only $10 \%$ laser power $(0.47 \mathrm{~mW})$ to avoid radiation damage. The characteristic Raman peaks are all clearly

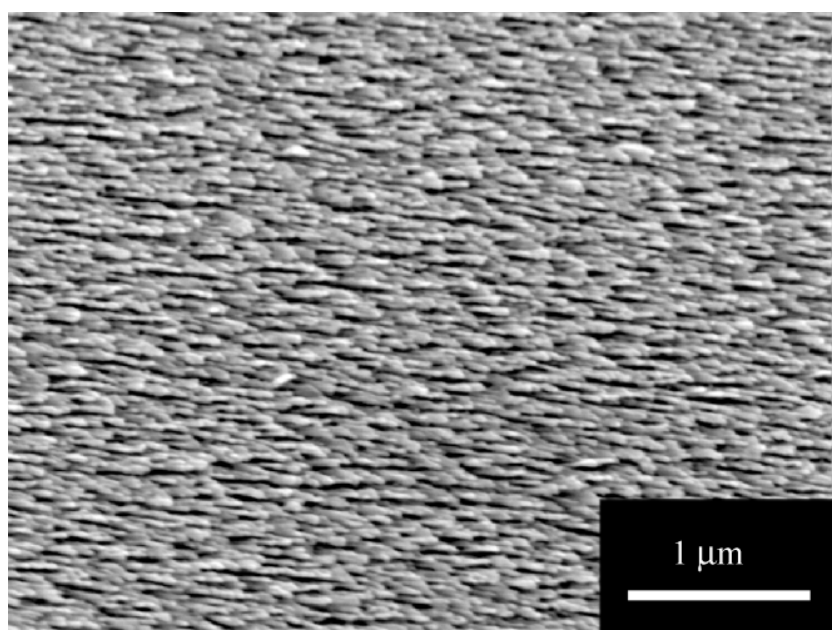

Figure 3 A typical SEM image showing the morphology of Ag nanorods used as the SERS substrate in this study

observed for each of the three isomers even at a concentration of $10^{-8} \mathrm{~mol} / \mathrm{L}$, suggesting that the SERS technique is able to detect chlorobiphenyls even at such a low concentration.

Figure 4(d) shows a comparison of the SERS spectra of the three isomers at a concentration of $10^{-6} \mathrm{~mol} / \mathrm{L}$. At this concentration the three spectra show the common features mentioned above around 1600, 1280, 1030, and $1000 \mathrm{~cm}^{-1}$ (the region around $3100 \mathrm{~cm}^{-1}$ was not scanned). The spectra also clearly show the individual characteristic Raman peaks for the three isomers, i.e., the difference in the CCC bending (ring deformation) in-plane modes caused by the $\mathrm{Cl}$ atom replacement. The spectra suggest that by using Ag nanorods as substrates, the SERS technique is capable of detecting chlorobiphenyls at trace levels and is capable of recognizing the isomers at low concentrations.

\section{Concluding remarks}

We have demonstrated a simple method to detect and recognize the isomers of chlorobiphenyls, even in trace amounts, by using the SERS technique with Ag nanorods as substrates, based on an understanding of Raman characteristics of these compounds. This method might be also applicable to the detection of PCBs, which is crucial for the effective removal of these hazardous substances. 


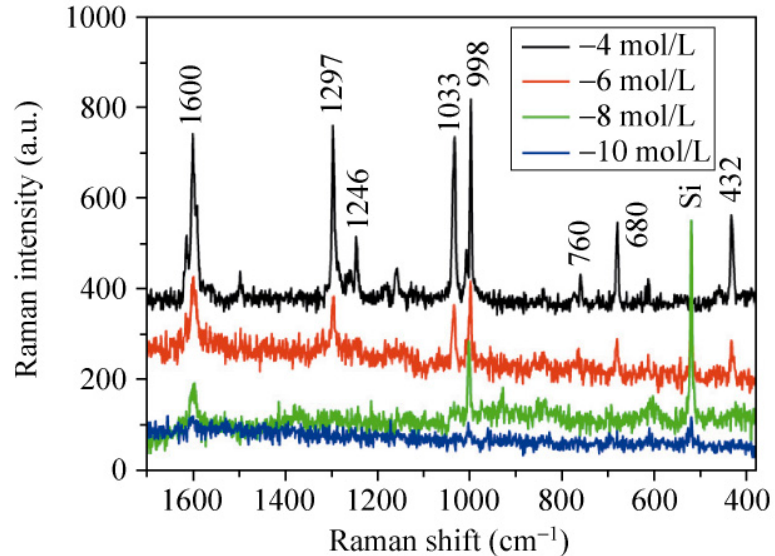

(a)

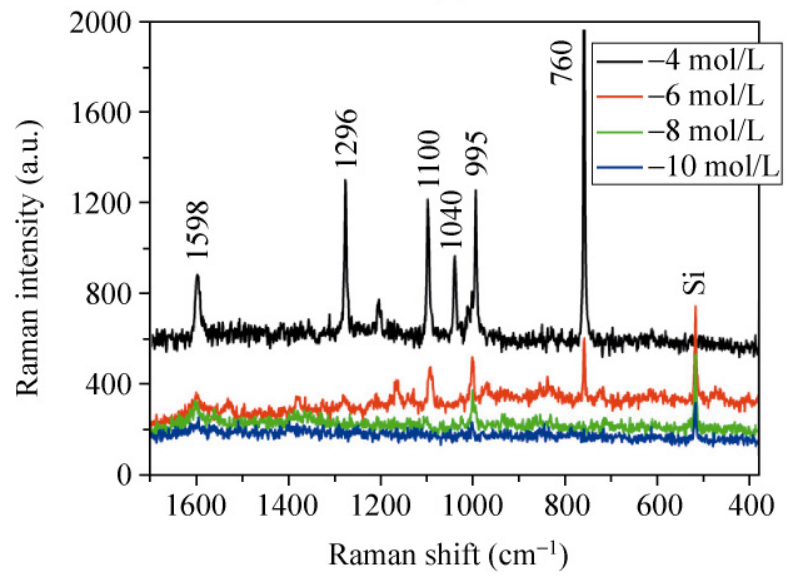

(c)

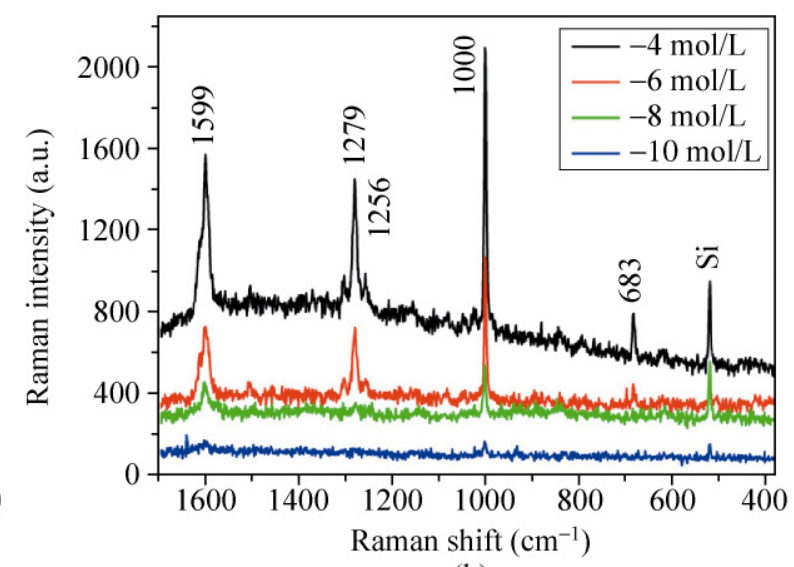

(b)

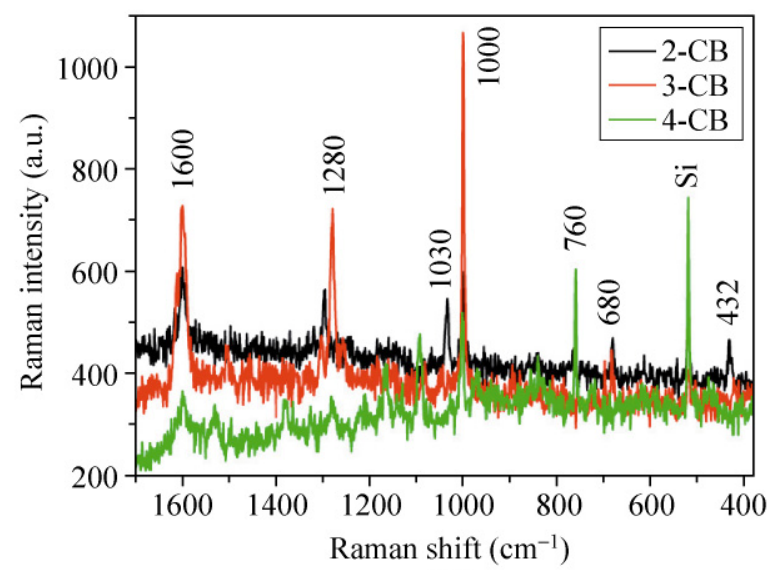

(d)

Figure 4 SERS spectra of (a) 2-chlorobiphenyl; (b) 3-chlorobiphenyl; (c) 4-chlorobiphenyl at concentrations from $10^{-4}$ to $10^{-10} \mathrm{~mol} / \mathrm{L}$ in acetone. (d) A comparison of the SERS spectra of the three isomers at a concentration of $10^{-6} \mathrm{~mol} / \mathrm{L}$

\section{Acknowledgements}

The authors are grateful for financial support from the National Natural Science Foundation of China (No. 50931002), and the National Basic Research Program of China (973 program, No. 2007CB936601).

Open Access: This article is distributed under the terms of the Creative Commons Attribution Noncommercial License which permits any noncommercial use, distribution, and reproduction in any medium, provided the original author(s) and source are credited.

\section{References}

[1] Ross, G. The public health implications of polychlorinated biphenyls (PCBs) in the environment. Ecotoxic. Environ. Safe. 2004, 59, 275-291.
[2] Cicchetti, D. V.; Kaufman, A. S.; Sparrow, S. S. The relationship between prenatal and postnatal exposure to polychlorinated biphenyls (PCBs) and cognitive, neuropsychological and behavioral deficits: A critical appraisal, Psychology in the Schools 2004, 41, 589-624.

[3] Ohtsubo, Y.; Kudo, T.; Tsuda, M.; Nagata, Y. Strategies for bioremediation of polychlorinated biphenyls. Appl. Microbiol. Biotechnol. 2004, 65, 250-258.

[4] Pitarch, E.; Serrano, R.; López, F. J.; Hernández, F. Rapid multiresidue determination of organochlorine and organophosphorus compounds in human serum by solid-phase extraction and gas chromatography coupled to tandem mass spectrometry. Anal. Bioanal. Chem. 2003, 376, 189-197

[5] Namiesnik, J.; Zygmunt, B. Selected concentration techniques for gas chromatographic analysis of environmental samples. Chromatographia 2002, 56, S9-S18

[6] Hong, J. E.; Pyo, H.; Park, S. -J.; Lee, W. Determination of hydroxy-PCBs in urine by gas chromatography/mass spectrometry with solid-phase extraction and derivatization.

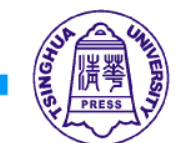


Anal. Chim. Acta 2005, 531, 249-256.

[7] Barra, R.; Cisternas, M.; Suarez, C.; Araneda, A.; Pinones, O.; Popp, P. PCBs and HCHs in a salt-marsh sediment record from South-Central Chile: Use of tsunami signatures and Cs-137 fallout as temporal markers. Chemosphere 2004, 55, 965-972

[8] Chu, H. Y. V.; Liu, Y. J.; Huang, Y. W.; Zhao, Y. P. A high sensitive fiber SERS probe based on silver nanorod arrays. Opt. Express 2007, 15, 12230-12239.

[9] Sun, X. Z.; Lin, L. H.; Li, Z. C.; Zhang, Z. J.; Feng, J. Y. Novel $\mathrm{Ag}-\mathrm{Cu}$ substrates for surface-enhanced Raman scattering. Mater. Lett. 2009, 63, 2306-2308.

[10] Isola, N. R.; Stokes, D. L.; Vo-Dinh, T. Surface enhanced Raman gene probe for HIV detection. Anal. Chem. 1998, 70, 1352-1356.

[11] Tripp, R. A.; Dluhy, R. A.; Zhao, Y. P. Novel nanostructures for SERS biosensing. Nano Today 2008, 3, 31-37.

[12] Zhao, Y. P.; Chaney, S. B.; Zhang, Z. Y. Absorbance spectra of aligned $\mathrm{Ag}$ nanorod arrays prepared by oblique angle deposition, J. Appl. Phys. 2006, 100, 063527.

[13] Tan, R. Z.; Agarwal, A.; Balasubramanian, N.; Kwong, D. L.; Jiang, Y.; Widjaja, E.; Garland, M. 3D arrays of SERS substrate for ultrasensitive molecular detection, Sensor. Actuat. A-Phys. 2007, 139, 36-41.

[14] Moskovits, M. Surface-enhanced spectroscopy. Rev. Mod. Phys. 1985, 57, 783-826.

[15] Kudelski, A. Analytical applications of Raman spectroscopy.
Talanta 2008, 76, 1-8.

[16] Vo-Dinh, T.; Houck, K.; Stokes, D. L. Surface-enhanced Raman gene probes. Anal. Chem. 1994, 66, 3379-3383

[17] Hering, K.; Cialla, D.; Ackermann, K.; Dorfer, T.; Moller, R,; Schneidewind, H.; Mattheis, R.; Fritzche, W.; Rosch, P.; Popp, J. SERS: A versatile tool in chemical and biochemical diagnostics. Anal. Bioanal. Chem. 2008, 390, 113-124.

[18] Zhang, X. Y.; Zhao, J.; Whitney, A. V.; Elam, J. W.; Van Duyne, R. P. Ultrastable substrates for surface-enhanced Raman spectroscopy: $\mathrm{Al}_{2} \mathrm{O}_{3}$ overlayers fabricated by atomic layer deposition yield improved anthrax biomarker detection. J. Am. Chem. Soc. 2006, 128, 10304-10309.

[19] Wang, Y.; Li, Y. S.; Zhang, Z. X.; An, D. Q. Surfaceenhanced Raman scattering of some water insoluble drugs in silver hydrosols. Spectrochim. Acta A 2003, 59, 589-594.

[20] Huang, L.; Tang, F.; Shen, J. Hu, B. X.; Meng, Q. J.; Yu, T. A simple method for measuring the SERS spectra of waterinsoluble organic compounds. Vib. Spectrosc. 2001, 26, 15-22.

[21] Zhou, Q.; Li, Z. C.; Yang, Y.; Zhang, Z. J. Arrays of aligned, single crystalline silver nanorods for trace amount detection. J. Phys. D: Appl. Phys. 2008, 41, 152007.

[22] Fleming, G. D.; Golsio, I.; Aracena, A.; Celis, F.; Vera, L.; Koch, R.; Vallette, M. C. Theoretical surface-enhanced Raman spectra study of substituted benzenes. I. Density functional theoretical SERS modelling of benzene and benzonitrile. Spectrochim. Acta A 2008, 71, 1049-1055. 